\title{
MAKNA RAGAM BAHASA JEPANG DANSEIGO DALAM \\ KOMIK DORAEMON VOLUME 3
}

\author{
Vamelia Aurina Pramandhani ${ }^{1}$ \\ ${ }^{1}$ Fakultas Bahasa dan Budaya, Universitas 17 Agustus 1945 Semarang (author 1) \\ email: vamelia-aurinapramandani@untagsmg.ac.id
}

\begin{abstract}
Japanese has a different form of conversational skills from other languages in the world, namely the Danseigo language variety and the Joseigo language variety. Danseigo is a language variety that is often used by men in Japan when communicating. Danseigo is a male language that tends to be rude and informal. Danseigo is rarely found during formal events. Usually men use standard Japanese or use keigo if the other person is a respectable person. The formulation of the problem in this study is what is the meaning and function of shuujoshi in danseigo found in the Doraemon comic volume 3? The purpose of this research is to find out the meaning and function of shuujoshi in danseigo found in Doraemon comic volume 3. The research method used is descriptive qualitative. The source of data used in the analysis of this research is a written source, namely the comic "Doraemon volume 3". In this comic, a form of conversation is found that uses a variety of languages and seigo. In addition, the use of shuujoshi (sound at the end of sentences) ( sa, kana/na, yo, ze, zo) and the use of ninshou daimeishi (boku, kimi, omae, aitsu, soitsu) were also found. This is because the comic characters are dominated by boys. Therefore, the use of danseigo is found in the Doraemon comic Volume 3.
\end{abstract}

Keywords: variety of language, Japan Language, Danseigo, Joseigo

\begin{abstract}
ABSTRAK
Bahasa Jepang memiliki bentuk keterampilan dalam percakapan yang berbeda dengan bahasa lain didunia, yaitu ragam bahasa Danseigo dan ragam bahasa Joseigo. Ragam bahasa danseigo adalah ragam bahasa yang sering dipakai oleh pria di Jepang ketika berkomunikasi. Danseigo merupakan bahasa laki - laki yang cenderung kasar dan nonformal. Jarang ditemukan danseigo ketika acara formal. Biasanya pria menggunakan bahasa Jepang standart atau menggunakan keigo jika lawan bicaranya merupakan orang terhormat. Rumusan masalah pada penelitian ini yaitu bagaimana makna dan fungsi shuujoshi dalam danseigo yang ditemukan dalam komik Doraemon volume 3? Tujuan peelitian ini adalah untuk mnegetahui makna dan fungsi shuujoshi dalam danseigo yang ditemukan dalam komik Doraemon volume 3. Metode penelitian yang digunakan adalah deskriptif kualitatif. Sumber data yang digunakan dalam analisis penelitian ini adalah sumber tertulis yaitu komik "Doraemon volume 3". Dalam komik ini ditemukan bentuk percakapan yang menggunakan ragam bahasa danseigo. Selain itu, juga ditemukan pemakaian shuujoshi (bunyi pada akhiran kalimat) ( sa, $\sim k a n a / n a, \sim y o, \sim z e, \sim z o$ ) dan penggunaan ninshou daimeishi (boku, kimi, omae, aitsu, soitsu). Hal ini disebabkan karena tokoh komiknya didominasi oleh anak laki laki. Maka dari itu penggunaan danseigo diketemukan dalam komik Doraemon Volume 3.
\end{abstract}

Kata kunci: Ragam bahasa, Bahasa Jepang, Danseigo, Joseigo 


\section{PENDAHULUAN}

\section{Latar Belakang}

Bahasa telah menjadi sebuah satu kesatuan pada diri setiap orang. Bahasa juga merupakan tanda yang jelas dari kepribadian manusia. Manusia yang berperan sebagai makhluk sosial dalam suatu kehidupan, sangat bergantung pada bahasa sebagai alat untuk berkomunikasi satu dengan yang lain. Selain untuk alat komunikasi, bahasa juga dapat dipakai untuk mengetahui dan mempelajari suatu karakter, pendidikan, latar belakang sosial serta sifat dari seseorang. Secara umum bahasa digunakan sebagai alat untuk menyatakan ekspresi diri, alat komunikasi, alat integrasi dan adaptasi sosial dan alat kontrol sosial.

Bahasa Jepang (日本語; romaji: Nihongo) merupakan bahasa resmi penduduk Jepang dengan jumlah penutur 127 juta jiwa. Bahasa Jepang dibagi atas dua bagian yaitu bahasa tulisan dan bahasa lisan. Bahasa tulisan dalam bahasa Jepang terbagi menjadi beberapa tulisan bahasa Jepang yang diadaptasi dari tulisan bahasa China (漢 字/kanji), yang diperkenalkan pada abad keempat Masehi. Sebelum ini, orang Jepang tidak mempunyai sistem penulisan sendiri. Penulisan huruf dalam bahasa Jepang dibagi atas 3 jenis yakni:

a. Aksara Kanji (漢字) yang berasal dari China

b. Aksara Hiragana (ひらがな) dan

c. Aksara Katakana (カタカナ)

Bentuk tulisan hiragana dan karakana tercipta setelah tulisan kanji. Sebelumnya tulisan kanji telah dikembangkan dari abad ke delapan Masehi oleh seorang rohaniawan Buddha di Cina. Tujuan dikembangkannya tulisan tersebut adalah untuk dapat membantu dalam melafalkan karakter tulisan bahasa Cina. Setelah kanji masuk dalam literasi bahasa Jepang, terciptalah dua jenis huruf baru yaitu hiragana dan katakana. Huruf hiragana dan katakana ini dipengaruhi oleh bentuk fonetik dari bahasa Sansekerta. Bukti yang menyatakan bahwa kedua jenis huruf tersebut mendapat pengaruh dari bahasa Sansekerta adalah adanya urutan dalam penulisannya. Selain kedua jenis huruf tersebut, dalam penulisan bahasa Jepang terdapat satu lagi ahliaksara yakni romaji. Romaji adalah tulisan yang digunakan untuk dapat memudahkan ketika membaca tulisan bahasa Jepang yang ditulis dengan menggunakan huruf Alphabet. Literasi bahasa Jepang yang diketahui hingga saat ini, merupakan gabungan dari ketiga jenis huruf tersebut. Tulisan kanji berfungsi untuk menyatakan arti dasar suatu kata (nomina, verba, adjektiva). Selanjutnya fungsi dari hiragana yaitu mengubah arti dasar dari suatu kata yang ditulis setelah kanji. Namun penulisan dari dua jenis huruf tersebut harus tetap disesuaikan dengan peraturan tata bahasa Jepang.

Selain bahasa tulisan, dalam bahasa Jepang juga terdapat bahasa lisan. Bahasa Jepang lisan dibagi atas dua bentuk Hyoujungo (標準語) dan Kyoutsugo (共通語). Hyoujungo adalah bentuk bahasa lisan yang berisi tuturan standart yang diajarkan di sekolah dan juga berfungsi sebagai bahasa pengantar dalam dunia pertelevisian segala situasi yang bersifat resmi atau formal. Sedangkan Kyoutsugo (共通語) adalah bentuk penuturan yang digunakan petutur dalam aktifitas keseharian. Untuk bahasa lisan sendiri juga terbagi menjadi tiga bentuk lainnya yaitu bentuk kesopanan, dialek dan gender.

Penyampaian suatu bahasa membutuhkan keterampilan dalam berkomunikasi. Keahlian dalam menguasai berbagai bahasa merupakan suatu keterampilan yang luar biasa, karena banyak bahasa di seluruh dunia yang sulit untuk dipelajari. Salah satunya yaitu bahasa Jepang. Bahasa Jepang memiliki dua jenis dialek sosial yang didasarkan 
pada perbedaan gender yakni ragam bahasa pria (danseigo) dan ragam bahasa wanita (joseigo).

\section{a. Ragam Bahasa Pria (男性/Danseigo)}

Danseigo adalah bahasa lisan yang dituturkan oleh kaum pria karena bentuk bahasa lisan ini yang bersifat kuat. Kata - kata yang termasuk dalam danseigo dalam bahasa Jepang antara lain ore, oyaji, ofukuro. Lalu partikel - partikel yang sering digunakan pada akhir biasa dipakai pada bagian akhir kalimat (shuujoshi) seperti zo, ze dan sebagainya. Danseigo digunakan dalam situasi yang cenderung tidak resmi. Sedangkan dalam situasi yang resmi, tidak diketemukan perbedaan bahasa lisan pada penutur pria dan wanita (Takamizawa, 2002 : 176).

\section{b. Ragam Bahasa Wanita (女性語/Joseigo)}

Joseigo merupakan suatu variasi bahasa Jepang lisan yang hanya digunakan oleh wanita di Jepang yang bertujuan untuk memunculkan refleksi feminimitas. Joseigo juga bisa disebut sebagai onna kotoba. Adanya bahasa lisan yang dibedakan oleh jenis kelamin tersebut merupakan ciri khas dari bahasa Jepang (Jorden, 1989 : 250).

Pada acara - acara tertentu di Jepang mungkin jarang terdengar pemakaian danseigo dan joseigo. Pemakaian kedua ragam bahasa ini tidak begitu tampak pada situasi - situasi resmi. Namun dalam situasi percakapan sehari - hari sering mendengar ragam bahasa ini. Tidak jarang kedua ragam bahasa ini dipakai dalam berbagai siaran radio atau televisi seperti dalam acara drama, film, atau acara acara lainnya. Pada media lain kedua ragam bahasa ini pun dapat kita lihat pada majalah, novel, cerita pendek, buku komik, pada kegiatan surat - menyurat, dan sebagainya.

Para penutur bahasa Jepang sebagai bahasa ibu (bogo) mungkin sudah terbiasa dengan danseigo dan joseigo, tetapi bagi orang Indonesia keberadaan danseigo dan joseigo terkadang menjadi salah satu kesulitan ketika mempelajari bahasa Jepang. Diketahui saat pertemuan pertama antara penutur dan lawan tutur akan memakai bahasa resmi atau bahasa standar. Tetapi apabila hubungan antara keduanya sudah akrab, dalam pembicaraan diantara mereka akan tampak perubahan variasinya.

Berdasarkan pernyataan tersebut menjadi alasan penulis untuk dapat mengembangkan makna dan fungsi dari penggunaan shuujoshi sebagai penanda pada ragam bahasa lisan pria (danseigo).

\section{Rumusan Masalah dan Tujuan Penelitian}

Penulis telah merumuskan masalah yang akan dianalisis dalam penelitian ini yaitu

1. Bagaimana makna shuujoshi danseigo yang ditemukan dalam komik Doraemon volume 3?

2. Bagaimana fungsi shuujoshi danseigo yang ditemukan dalam komik Doraemon volume 3 ?

Tujuan daripada penelitian kali ini penulis akan menjelaskan tentang makna dan fungsi shuujoshi danseigo yang ditemukan dalam komik Doraemon volume 3, agar para pembaca dapat mengetahui makna shuujoshi yang ditemukan pada komik tersebut.

\section{Ruang Lingkup Penelitian}

Penulis meneliti tentang ragam bahasa Jepang Danseigo dan Joseigo yang terdapat pada komik Doraemon volume 3. Penulis menggunakan sumber data pada komik Doraemon volume 3 ini, karena penulis telah menemukan begitu banyak bentuk kalimat pada dialog percakapan dengan menggunakan ragam bahasa Jepang yaitu Danseigo (ragam bahasa laki - laki) dan Joseigo (ragam bahasa perempuan). 
Karena dalam komik ini banyak sekali tokoh anak laki - laki, maka terdapat banyak sekali Shuujoshi Danseigo.

\section{2. TEORI DAN TINJAUAN PUSTAKA}

\section{Tinjauan Pustaka}

\section{Konsep Sosiolinguistik}

Menurut Nababan (1992:1-3) bahasa merupakan ciri khas paling manusiawi yang membedakannya dari makhluk - makhluk lain. Ilmu yang mempelajari tentang hakekat dan karakteristik dari bahasa ini disebut ilmu linguistik. Kajian bahasa dengan dimensi kemasyarakatan disebut sosiolinguitik. Istilah sosiolinguistik jelas terdiri dari dua unsur kata yaitu: sosio dan linguistik. Jadi arti linguistik adalah ilmu yang mempelajari atau membicarakan bahasa, khususnya unsur-unsur bahasa (fonem, morfem, kata, kalimat) dan hubungan antara unsur - unsur itu (struktur), termasuk hakekat dan pembentukan unsur - unsur itu. Unsur sosio berhubungan dengan sosial yakni segala yang ada hubungannya dengan masyarakat serta fungsi dari kemasyarakatan.

Maka dari itu sosiolinguistik adalah studi dari bahasa yang berhubungan dengan penutur bahasa sebagai anggota masyarakat. Dapat dikatakan juga bahwa sosiolinguistik merupakan ilmu yang membahas tentang aspek bahasa dalam kemasyarakatan yang dikhususkan pada variasi bahasa yang berkaitan dengan faktor sosial. Salah satu topik umum dalam pembahasan sosiolinguistik yang akan dibahas adalah mengenai penggunaan ragam bahasa.

\section{Landasan Teori \\ 1. Teori Danjo atau Gender}

Danjo adalah ragam bahasa Jepang yang tercipta dari dua huruf kanji yakni kanji (男) yang berarti pria/ laki - laki dan kanji (女) yang berarti perempuan. Dalam ilmu sosiolinguistik, istilah gender mengacu pada perbedaan jenis kelamin dari penutur bahasa tersebut (pria atau wanita). Berbagai pengamat bahasa telah menyatakan bahwa terdapat perbedaan pengguna bahasa oleh pria dan wanita dalam berbagai masyarakat di dunia.

\section{Perbedaan antara Danseigo dan Joseigo}

Ragam bahasa lisan memiliki perbedaan yang mencolok dari penerapan danseigo dan joseigo pada kehidupan sehari - hari. Perbedaan ini terlihat sejak anak - anak di Jepang berusia 3 tahun. Ragam bahasa lisan ini juga disebut dengan bahasa gender. Gender menjadi peran utama dalam pemaknaan suatu bahasa lisan dan bukan ditentukan secara gramatikal. Pererapan bahasa lisan berdasarkan gender bagi beberapa kelompok penutur tertentu, ada yang diterapkan secara berkebalikan. Saat laki - laki bicara dengan menggunakan joseigo, maka penutur dianggap memiliki kepribadian seperti perempuan (waria). Namun hal ini tidak menyalahi aturan secara gramatikal. Seangkan jika seorang penutur wanita bicara dengan menggunakan danseigo, maka akan menciptakan kesan sifat yang kasar. Perbedaan danseigo dan joseigo dapat ditemukan dalam beberapa aspek kebahasaannya seperti: kata benda (meishi), kata ganti (dameishi), kata akhiran (shuujoshi) dan kata seru (kandoushi).

\section{Penggunaan Danseigo dalam Shuujoshi}

Bahasa Jepang sangat identik dengan partikel. Banyak jenis partikel yang digunakan dalam penulisan kalimat bahasa Jepang. Letak partikel biasanya berada di tengah dan di akhir kalimat. Ada beberapa partikel yang ditemukan di akhir kalimat yang disebut shuujoshi. Fungsi partikel ini muncul ketika sedang menggunakan bahasa Jepang lisan. Shuujoshi diucapka dengan diikuti 
intonasi suara yang bertujuan untuk menyampaikan suatu emosi yang sedang dirasakan oleh penutur. Penerapan shuujoshi juga dapat berfungsi untuk memperhasul atau mempertegas kalimat yang dituturkan. Beberapa partikel shuujoshi yang dipakai dalam bahasa Jepang lisan ini juga dibedakan berdasarkan gender.

a. Shuujoshi untuk danseigo diantaranya sebagai berikut:

1. $\boldsymbol{Z} \boldsymbol{e}$ : berfungsi untuk menyatak suatu keinginan Contoh : "Shasshin toru ze." = "ayo kita berphoto!"

2. Zo: Meski terdengar kasar, namun partikel ini berfungsi untuk mempertegas suatu pernyataan. Selain itu juga dapat diterapkan untuk menarik perhatian lawan tutur.

Contoh : "Minna ikuzo!" = "Ayo semuanya!!"

3. Na: Berfungsi sebagai larangan atau perintah. Namun, jika diucapkan dengan intonasi suara yang rendah, maka akan berubah fungsi menjadi suatu pernyataan pendapat.

Contoh : "Kono sushi wo taberuna!" = "Jangan makan sushi ini!" (larangan).

\section{METODE PENELITIAN}

\section{Jenis Penelitian}

Pada penelitian kali ini, penulis menerapkan metode penelitian deskriptif kualitatif. Penelitian deskriptif merupakan salah satu cara penelitian yang dilakukan dengan menggunakan suatu objek yang sesuai dengan realita untuk diinterpretasikan Penelitian deskriptif juga disebut penelitian non eksperimen. Pada penerapan metode penelitian ini peneliti dilarang melakukan manipulasi variabel dan harus menyajikan fakta. Sehingga peneliti murni hanya mendeskripsikan hasil penelitiannya.

Deskriptif kualitatif adalah metode penelitian yang menerapkan metode pengumpulan data yang didapat secara langsung dari narasumber, baik secara tulisan maupun lisan. Pengumpulan data dengan menggunakan metode ini dilakukan dengan cara wawancara langsung kepada narasumber, melakukan observasi ke lapangan serta juga didapatkan dari hasil diskusi. Dari data - data yang dikumpulkan seorang peneliti, akan dikembangkan menjadi sebuah rangkuman data yang kompleks.

\section{II.Sumber Data}

Sumber data yang digunakan dalam penelitian ini adalah sumber tertulis yaitu komik "Doraemon volume 3". Dalam komik ini, penulis menemukan berbagai macam bentuk kalimat percakapan yang berisi tentang penggunaan danseigo dan joseigo oleh tokoh - tokoh karakter tersebut baik dalam pemakaian shuujoshi ( sa, kana/na, yo, ze, zo) dan pemakaian ninshou daimeishi (boku, kimi, omae, aitsu, soitsu).

\section{Deskripsi Sumber Data}

Doraemon adalah sebuah karya fiksi karangan dari komikus (mangaka) di Jepang Fujiko F. Fujio yang menceritakan mengenai kehidupan seorang anak kelas 5 sekolah dasar yang bernama Nobi Nobita. Nobita dikenal sebagai anak yang pemalas dan sering mendapatkan nilai jelek disetiap mata pelajarannya. Suatu ketika ia didatangi oleh sebuah robot kucing bernama Doraemon yang datang dari abad ke-22. Doraemon sengaja dikirimkan ke masa Nobita hidup saat itu untuk membantu Nobita agar menjadi orang yang rajin dan pintar. Sehingga 
keturunan Nobita kelak dapat menikmati kesuksesannya daripada harus mengalami penderitaan yang disebabkan oleh kebodohan Nobita.

Sejak bertemu Doraemon, nasib Nobita sedikit demi sedikit mulai berubah. Namun Nobita malah terlihat semakin malas karena ia selalu mengandalkan alat yang dimiliki oleh Doraemon yang dikeluarkan dari kantung ajaibnya. Doraemon memiliki sebuah kantung ajaib yang terdapat di perutnya. Kantong ajaib ini menyimpan berbagai alat canggih yang dibawa dari masa depan. Contohnya seperti baling - baling bambu, pintu ajaib dan sebagainya.

\section{Validitas Sumber Data}

Penulis menggunakan sumber data pada komik Doraemon volume 3 ini, karena menemukan beberapa jenis kalimat dengan menggunakan ragam bahasa Jepang yaitu danseigo dan joseigo. Karena dalam komik ini banyak sekali tokoh anak laki - laki, maka banyak ditemukan shuujoshi danseigo (partikel yang muncul khusus untuk ragam bahasa laki - laki).

Tokoh utama komik ini adalah Doraemon yang merupakan seekor robot kucing dan lebih cenderung menggunakan ragam bahasa laki - laki (danseigo). Dan juga tokoh utama kedua ialah seorang anak sekolah dasar bernama Nobi Nobita juga seorang anak laki - laki. Nobita sendiri memiliki banyak teman yang juga kebanyakan anak laki - laki yang seusia dengannya. Tentu saja saat mereka berkomunikasi lebih sering menggunakan ragam bahasa laki - laki (danseigo) daripada menggunkan bahasa formal (teineigo).

Sedangkan untuk ragam bahasa perempuan (joseigo) juga ditemukan penggunaannya, namun lebih sedikit dari penggunaan ragam bahasa laki - laki (danseigo). Dalam komik ini, tokoh anak perempuan lebih sering mengarah ke Shizuka, teman sekelas Nobita dan ibu dari Nobita.

Meskipun begitu, penulis telah menemukan masing - masing contoh kalimat yang mewakili bentuk ragam bahasa laki - laki (danseigo) dan ragam bahasa perempuan (joseigo).

\section{Metode Pengumpulan Data}

Penulis memilih untuk menggunakan metode penilitian deskriptif kuantitatif dan memilih sumber data primer (utama). Data yang akan dianalisis berupa dialog dalam komik Doraemon volume 3. Dalam komik ini ditemukan banyak dialog dimana para penuturnya menggunakan danseigo dan joseigo. Pertama - tama penulis membaca terlebih dahulu buku yang dijadikan sebagai sumber data. Kemudian penulis mulai mengumpulkan jenis data yang akan dianalisis.

\section{PEMBAHASAN}

\section{Penggunaan Shuujoshi Pada Ragam Bahasa Danseigo}

a. Penggunaan shuujoshi $\sim \boldsymbol{y o}$

Nobita ： 人間だけ入れかえても、だめなんだよ。 Biarpun orangnya diganti, tapi lainnya jangan.

Doraemon： 何とかしよう。

Harus melakukan sesuatu

Nobita ：やあ君たち、どんなぐあい?

Hey kalian, bagaimana dengan kalian?

Suneo ：うん、わるくない。

Ya...tidak burukjuga. 
Nobita： おばさん、さっきのことあやまってたよ。

Oh iya, bibi tadi sudah minta maaf lho.

Shizuka ：あらそう?このおこづかい、スネオさんのしかられちんらし いわ。

Eh, benarkah? Oh iya uang saku ini, barangkali menyebabkan

Suneo dimarahi.

Suneo ：公平に見て、君にも、反省すべき点があるよ。

Itu berarti kita sendiri yang harus intropeksi diri lho.

(Doraemon volume 3, hal.35)

Analisis:

Dialog di atas memiliki tema menukar ibu. Nobita, Suneo dan Shizuka mencoba saling bertukar ibu masing - masing dan merasakan perbedaannya. Shuujoshi $\sim$ yo pada percakapan diatas mengartikan penegasan. $\sim \boldsymbol{y o}$ seperti yang diucapkan Nobita memiliki arti yaitu memberitahukan sesuatu yang bersifat menegaskan namun bukan memerintah. Sedangkan $\sim \boldsymbol{y o}$ yang diucapkan Suneo memiliki makna yakni memerintah Nobita dan semuanya untuk intropeksi diri.

b. Penggunaan shuujoshi $\sim$ sa

Nobita ：火事だああ。。。！！！ KEBAKARANNN ...!!!

Ayah ： えつ、どこ?どこ?

ごめんな。忘れてたわけじゃないけどさ。昨夜、ママのボー ナスの使いみちを計算したんだ。

He? Dimana? Dimana? Oh iya, maaf ya. Bukannya ayah

melupakannya. Tadi malam ayah telah menghitung bonus dengan mama.

(Doraemon volume 3, hal.78)

Analisis:

Dialog di atas menceritakan tentang malam natal yang mendapat banyak bonus. Orang tua Nobita lupa menghitung bonus yang sudah didapatkan oleh mereka. Shuujoshi $\sim \boldsymbol{s a}$ yang diucapkan papa Nobita memiliki makna yaitu dia ingin memberi penegasan namun secara halus bahwa papa Nobita sebenarnya tidak lupa seperti yang dipikirkan oleh Nobita.

c. Penggunaan shuujoshi $\sim$ ze

Takeshi ：今日は、ぜったいに勝つんだ!エラーしたらぶんなぐる。

Hari ini, kita pasti menang! Jika ada yang melakukan kesalahan, maka akan mendapat pukulan.

Nobita ：ひやああ。。。！！

Uwaaaaaa....!!!

Suneo ：さあ、三しんにとっちゃおうぜ。

Ayo, lakukan pukulan ke 3!

(Doraemon volume 3, hal.90)

\section{Analisis :}

Pada saat bermain baseball, Nobita selalu melakukan kesalahan. Karena Nobita sama sekali tidak bisa bermain baseball dan takut terkena bola. Nobita juga tidak bisa menangkap bola yang dipukul. Suneo dan Takeshi mengetahui akan hal itu, maka mereka berdua selalu menempatkan Nobita sebagai pemukul atau penangkap bola. Jika tidak bisa melakukannya, maka Nobita akan mendapat pukulan dari 
Takeshi. Akhiran ze pada dialog yang diucapkan Suneo bermakna bahwa Suneo sangat percaya diri jikalau Nobita pasti tidak dapat menagkap bola. Shuujoshi ini biasanya digunakan bila penutur sedang bersemangat dan percaya diri dalam melakukan sesuatu.

d. Penggunaan shuujoshi $\sim$ zo

Doraemon： ハクション！！！！

\section{HATCHINN!!}

Nobita : じうしたの?

Ada apa?

Doraemon： 僕は風をひているんだぞ。

Aku sedang sakit flu tahu!

(Doraemon volume 3, hal.86)

Analisis :

Nobita dan Doraemon sedang berjalan bersama di taman. Sebelumnya Doraemon sedang sakit, namun Nobita tidak menyadarinya dan terus saja berjalan. Sampai pada akhirnya Doraemon bersin dengan sangan kencang. Nobita malah bertanya seperti orang bodoh, dan hal ini membuat Doraemon marah kepada Nobita lalu membentaknya. Doraemon mengatakan sesuatu dengan akhiran $\sim$ zo yang mempunyai makna penegasan dalam menyampaikan sesuatu. Biasanya si penutur yang menggunkan akhiran ini, nada bicaranya terdengar begitu kasar dan biasanya diucapkan dengan cara berteriak.

e. Penggunaan shuujoshi $\sim$ da ne

Doraemon：それをカードに書いて、ここへ入れる。

Lalu tulis sesuatu dikertas ini, lalu masukan kesini.

Nobita：すると、かわりに何でもしてくれるんだね。

Lalu akudapat bebas berbuat apa saja.

Doraemon : そうはいかない。やるのは、君だ。

Itu tidak bisa. Yang melakukan ya kamu.

Nobita : なんだ、つまらん。

Apaan?? Membosankan.

(Doraemon volume 3, hal.54)

\section{Analisis :}

Doraemon memberikan sebuah alat yaitu jam dinding yang bisa berjalan. Jam ini dapat berjalan kemana si pemilik jam ini pergi. Jam ini berfungsi untuk menjadwalkan semua kegiatan yang telah ditulis dan dimasukan ke dalamnya. Nobita sangat senang mendengarnya dan berucap dengan menggunakan shuujoshi da ne yang bermakna ungkapan rasa senang akan sesuatu yang akan dia dapat atau akan dia lakukan.

f. Penggunaan shuujoshi $\sim$ da yo na

Nobita : もう、やめようか。 Ah...berhenti sajalah.

Doraemon： みこみなさそうだよな。 Kau ini suka sekali mencari penyakit saja.

Nobita : すてちゃえ。

Buang sajalah.

(Doraemon volume 3, hal.122) 


\section{Analisis :}

Doraemon memberikan Nobita alat yang dapat membuat tubuh menjadi tidak terlihat atau menghilang. Alat itu berbentuk panah yang ditancapkan pada kepala dan selanjutnya si pemakai alat tersebut akan menghilang. Nobita memakai alat ini untuk jahil dan mengintip seseorang. Perbuatannya itumerugikan banyak orang. Sadar akan hal itu merupakan sesuatu yang tidak berkenan, maka dia berencana menghentikan aksinya. Doraemon membalas dengan ucapan yang diakhiri $\sim$ dayo na yang bermakna menyetujui ucapan dari lawan tutur dan cenderung mengeluhkan sesuatu.

g. Penggunaan shuujoshi $\sim$ da $\boldsymbol{n a}$

Doraemon : はじめに、うそだとことわっておいたのに。。

Pada awalnya memang berkata bohong..

Nobita : つい、本気にしちゃった。不思議だな。

Kemudian, menjadi kenyataan. Sungguh ajaib ya.

Doraemon：それでうそをつけば、どんなでたらめでも、本気にされる。

Kalau berbahong dengat alat ini,walaupun kamu sembrono pasti

terjadi sungguh-sungguh.

Nobita ：うそつきに行こう。

Ayo kita membuat kebohongan!

(Doraemon volume 3, hal.63)

\section{Analisis :}

Shuujoshi dana pada kalimat yang diucapkan oleh Nobita memiliki makna sebuah kekaguman akan melihat sesuatu. Arti lain dari dana ini yaitu sebuhan desahan pada saat menginginkan sesuatu namun tidak kunjung didapatkan. Hal ini lebih seperti sebuah harapan. Nobita mengatakan “不思議だな” karena dia sangat takjub dengan cara kerja alat yang dikeluarkan oleh Doraemon. Alat itu berupa paruh yang diletakkan di depan mulut. Kemudian jika berbohong, maka alat itu bisa mengubah kebohongan tersebut menjadi sebuah kenyataan.

\section{SIMPULAN}

Bahasa Jepang memilik dua jenis bahasa yakni formal dan informal. Bahasa formal digunakan ketika perkenalan atau pada suatu acara resmi dan berhadapan dengan orang yang kedudukannya lebih tinggi atau lebih dihormati. Sedangkan bahasa informal digunakan pada sesama teman yang sudah akrab atau dengan keluarga. Suatu keterampilan sangat dibutuhkan dalam penyampaian suatu bahasa. Bahasa Jepang mempunyai keterampilan yang berbeda dalam percakapan dengan bahasa lain di dunia yaitu adanya ragam bahasa Danseigo dan ragam bahasa Joseigo.

Danseigo adalah ragam bahasa Jepang lisan yang dipakai oleh laki - laki di Jepang. Umumnya danseigo merupakan bahasa lisan yang dapat memunculkan karakter sifat kasar dan non formal pada penuturnya yakni laki - laki. Danseigo jarang ditemukan saat ada acara formal. Biasanya pria menggunakan bahasa Jepang umum atau menggunakan keigo (bahasa sopan tingkat tinggi) jika lawan bicaranya merupakan orang terhormat.

Penggunaan shuujoshi pada danseigo bertujuan sebagai penegasan suatu kalimat. Bentuk shuujoshi dalam danseigo antara lain $\sim \boldsymbol{z e} ; \sim \boldsymbol{z o} ; \sim \boldsymbol{s a} ; \boldsymbol{n a}$ dan sebagainya. Setiap shuujoshi pada setiap kalimat memiliki makna yang berbeda. 
Makna tersebut diantaranya penegasan, larangan, pendapat dan keinginan yang ditentukan oleh konteks kalimat.

Pada komik Doraemon volume 3 ini banyak ditemukan bentuk percakapan yang menggunakan ragam bahasa danseigo. Karakter dalam komik ini juga didominasi oleh karakter anak laki - laki. Maka dari itu hasil yang ditemukan dalam analisis ini bahwa penggunaan ragam bahasa danseigo lebih dapat ditemukan ketika penutur dan lawan tutur dihadapkan pada situasi informal atau tidak resmi.

\section{DAFTAR PUSTAKA}

Fujio, Fujiko F. Doraemon Volume 3 . Jakarta: PT Elex Media Komputindo, Gramedia, 1992.

—. Doraemon Volume 3. Tokyo: Shogakukan, Inc, 1974.

Minna no Nihongo Sokyu I. Surabaya: International Multicultural (I'Mc) Center Press, 2012.

Joshi.Jakarta:Evergreen Japanese Course Chino Naoko.2008.

Ancangan Metode Penelitian dan Kajian Linguistik, Bandung: PT Refika Aditama Hendarto Supatra.1996.

Hidayat, R.S. Penulisan dan Gender. Makara Sosial Humaniora, 8(1), 9-15. 2004.

Coates, J. Women, Men and Language. London: Longman. 1986.

Introduction to Japanese linguistics, Hongkong: Graphicraft Typesetters limited Verhaar.M.W.J.1996.

Metode dan Aneka Teknik Analisis Bahasa, Jogjakarta: Duta Wacana University Press Sudjianto,D Ahmad.2007.

http://jurnal.untag-sby.ac.id/index.php/mezurashii/article/view/4656 